\title{
EFFECTS OF BILATERAL SPHENOPALATINE GANGLION BLOCK IN FUNCTIONAL ENDOSCOPIC SINUS SURGERY UNDER GENERAL ANESTHESIA
}

By

\author{
Nabil A. Sarhan ${ }^{1 *}$, Mohamed A. Fathalla ${ }^{1 ¥}$, Mohamed H. Alahmer ${ }^{1 I I}$, \\ Mostafa E. Mohamed ${ }^{2 \epsilon}$ and Medhat M Khalifa ${ }^{2 \epsilon}$
}

Departments of ${ }^{1}$ Otorhino-Laryngology and ${ }^{2}$ Anesthesia \& Intensive Care Faculty of Medicine ( ${ }^{\ddagger}$ Damietta, ${ }^{\mathbb{I}}$ Cairo, ${ }^{€}$ Assiut), Al-Azhar University

*Corresponding author: Nabil A. Sarhan, E-mail: nabelent@yahoo.com

\begin{abstract}
Background: Functional endoscopic sinus surgery (FESS) is considered as one of the most common surgical procedure. General anesthesia (GA) is usually required during FESS. Regional analgesic techniques can use during GA that is inhibits the intra- and the post-operative detrimental stimuli.

Objective: To evaluate the effects of bilateral sphenopalatine ganglion block (SPGB) in FESS by using different types of local anesthetic agents.

Patients and Methods: A double-blinded, randomized, controlled-trial study was performed on 80 patients undergoing FESS with bilateral SPGB under GA. This study was conducted at departments of Otorhinolaryngology and Anesthesia \& Intensive care, Al-Jafel International Hospital, Riyadh, KSA. The current study was conducted since May 2018 till January 2020. The patients were categorized into 4 groups; group I using (bupivacaine $0.5 \%$ ), group II using (ropavacine $0.75 \%$ ), group III using (xylocaine $2 \%$ ), and group IV using (saline) as a control group. Observed variables included hemodynamic parameters, surgical field visibility, intra-operative blood loss, post-operative analgesia use, and complications related to the used technique.
\end{abstract}

Results: Averages of the heart rate, mean arterial blood pressure, bleeding, operative time, and visual analogue scale (VAS) in the three groups were statistically significant different from the controls $(\mathrm{P}=000)$. The clarities of the operative field and bleeding amount in the three groups separately were statistically significant different from the controls $(\mathrm{P}=0.000)$. The differences in the post-operative complications in the three groups and the controls were statistically insignificant except for group III. The differences in the analgesics usage in the three studied groups and the controls were statistically insignificant except group I.

Conclusion: Using of bilateral SPGB in FESS under GA is proved to be of great importance in reducing the heart rate, arterial blood pressure, bleeding, operation time, and VAS in the studied groups. Further, xylocaine $2 \%$ is significantly reducing the post-operative complications. Also, bupivacaine $0.5 \%$ is significantly reducing the analgesics usage.

Keywords: Bilateral SPGB, FESS, Bupivacaine 0.5\%, Hemodynamics, Complications.

\section{INTRODUCTION}

Functional endoscopic sinus surgery (FESS) is currently a prevalent surgical technique in Rhinology specialty. It has a high success rate for symptomatic enhancement in patients with medically refractory chronic rhinosinusitis and chronic polypoid rhinosinusitis (Huang et al., 2015 and Di Mauro et al., 2018). 
General anesthesia (GA) is often needed during FESS, especially complex and prolonged cases. Local anesthetics, regional block, could be used as alternates to high-dose of analgesics to decrease their amount and side-effects (Ekici and Alagöz, 2019). Also, it's reasonable to prevent peri-operative rise in sympathetic tone by using a sufficient anesthetic depth and analgesia. These achieved using abundant narcotics that has significant post-operative drawbacks including reduced alertness, insufficient spontaneous breathing and increased nausea and vomiting (Shamil et al., 2018).

Regional analgesic procedures use during GA inhibits intra- and postoperative detrimental stimuli (Robbins et al., 2016), and, so, can be used as a superior alternate to increase the doses of narcotics avoiding their inappropriate drawbacks (Shamil et al., 2018). The sphenopalatine ganglion block (SPGB) was used efficiently as a single anesthetic procedure before removal of nasal packing, post- operative pain might be correlated with late functional recovery and it much contributes to dis-satisfaction with the procedure, late in returning to work and re-admission after surgical operations (Robbins et al., 2016 and Ekici \& Alagöz, 2019). Post-operative analgesia after FESS can be achieved through opioids, NSAIDs, topical/infiltration of local anesthetics and regional procedures like SPGB; SPGB is suspected to supply peri-operative analgesia after FESS (Xiong et al., 2017).

Combination of regional anesthesia with GA procedure could present as a best hemodynamic control standards, low perioperative opioid-use, minimize bleeding loss, and induce the highest levels of patients' satisfaction (Cho et al., 2011 and Al-Qudah, 2016). Reducing in surgical bleeding in FESS could be, also, enhance surgical field and surgeons' contentment and a reduced opioid-use may be transferred to a low post-operative nausea and vomiting, early- and recovery and hospital discharge (Shamil et al., 2018).

The aim of this study was to evaluate and compare the effects of bilateral SPGB by using different types of local anesthetic agent on the hemodynamics, surgical field, intra- operative blood loss, postoperative pain relief and analgesia usage, and post-operative complications.

\section{PATIENTS AND METHODS}

The current study was conducted since May 2018 till January 2020, after approval of the study protocol by the Local Ethical Committee. Furthermore, an informed consent was taken from each patient. A double-blinded, randomized controlled, clinical-trial, design was chosen to conduct this study. The study was carried out at Departments of Otorhinolaryngology and Anesthesia \& Intensive care, Al-Jafel International Hospital, Riyadh, KSA. Eighty adult patients from both sexes were recruited for this study. The patients were chosen according to American Society of Anesthesiologists (ASA) I-II (Mayhew et al., 2019). The patients' ages ranged from 18 to 60 years. The patients had different nasal sinus pathologies including chronic sinusitis and nasal polyposis.

Patients were scheduled to undergo FESS and randomly categorized into four equal groups. Group I using (bupivaciane $0.5 \%)$ : Received pre-emptive transoral 
bilateral SPGB after induction of GA, Group II using (ropavacine $0.75 \%$ ), Group III using (xylocaine 2\%), and Group IV (control group) using normal saline. The randomization was performed using randomized allocation software technique.

\section{Exclusion criteria:}

Pregnant and lactating women, patients with clinically significant cardiovascular, pulmonary, hepatic, neurologic or metabolic diseases and those with hypersensitivity to local anesthetic agent were excluded.

All patients received $2 \mathrm{mg}$ of midazolam intra-venously as a premedication 10min before the induction of GA with standard monitoring. GA was induced intra-venously with $2-3 \mathrm{mg} / \mathrm{kg}$ $1 \%$ propofol and $2 \mu \mathrm{g} / \mathrm{kg}$ fentanyl, and the trachea was intubated with a cuffed endotracheal tube under muscle relaxation with $0.5 \mathrm{mg} / \mathrm{kg}$-atracurium. Anesthesia was maintained with sevoflurane $2 \%$ in $50 \% \mathrm{~N} 2 \mathrm{O}$ in $\mathrm{O} 2$ with positive pressure ventilation then followed by ganglion block.

The intra-oral greater palatine canal approach to block the sphenopalatine ganglion was used (Wormald et al., 2005). The greater palatine foramen has a constant location posteromedial to the third maxillary molar and anteromedial to the maxillary tuberosity and pterygoid hamulus. The instruments required were a $5 \mathrm{~mL}$ syringe and a 25 -gauge needle. The needle was bent about 60 degree, approximately $25-30 \mathrm{~mm}$ from the tip. After using finger palpation to determine the location of greater palatine foramen, the needle was pushed through the mucosa until bone was encountered. With slight exploratory movements to localize the foramen, the needle slipped up the canal with ease. A negative pressure with aspiration ensured the correct position. Air bubbles or a bloody aspirate indicated entry into the nasopharynx or a vessel, in which case. The needle was withdrawn and repositioned. Thereafter, $2 \mathrm{~mL}$ of local anesthetic or saline was injected in each side of greater palatine canal. Standardized anesthetic management in this study was the maintenance of enough hypotension for producing an optimal surgical field.

Sevoflurane concentration in a stepwise fashion until a mean blood pressure of $65-70 \mathrm{mmHg}$ was achieved or the end-tidal concentration of sevoflurane reached $3 \%$. If blood pressure control was not achieved with a $3 \%$ sevoflurane concentration, incremental boluses of $1 \mu \mathrm{g} / \mathrm{kg}$ fentanyl were administered up to a total dose of $3 \mu \mathrm{g} / \mathrm{kg}$. When both drugs failed to achieve good surgical field, a bolus $0.5 \mathrm{mg} / \mathrm{kg}$ of esmolol, followed by $0.5 \mathrm{mg} / \mathrm{kg} / \mathrm{h}$ infusion a selective (B1adrenoreceptor antagonist), was given to induce the required hypotension. Bradycardia (heart rate $<50$ beats/min) was treated with atropine $(0.5 \mathrm{mg})$.

At the end of surgery, sevoflurane and $\mathrm{N}_{2} \mathrm{O}$ were discontinued. Residual neuromuscular block was antagonized with neostigmine $(0.04 \mathrm{mg} / \mathrm{Kg} \quad \mathrm{IV})$ and atropine sulphate $(0.01 \mathrm{mg} / \mathrm{Kg}$ IV). The trachea was extubated when adequate spontaneous ventilation and patient response to verbal commands were established. After surgery, the patients were admitted to the post-operative care unit (POCU). 
The following parameters were recorded:

1. The heart rate (HR) every $15 \mathrm{~min}$ during surgery.

2. Mean arterial blood pressure (MAP) was measured every 15 minute during surgery.

3. Assessment of surgical field: It was classified as clear, moderate-, and little-clarity.

4. Blood loss was measured in milliliters.

5. Duration of surgery (minutes).

6. Pain intensity was evaluated with a 10 visual analogue scale (VAS) scores (where 0 is defined as no pain at all and 10 as the worst possible pain) at 2, 6, 12 , and 24 hours post- operatively.

7. The time to first rescue pain medication and analgesic requirements were assessed. The patients received $30 \mathrm{mg}$ of ketolac intra-venous and $50 \mathrm{mg}$ of pethidine intra-muscular as required for post-operative supplemental analgesia, on request.

8. Complications including bleeding, nausea, vomiting, dental numbness, headache, and sense of retro-ocular pressure were recorded.

\section{Statistical analysis:}

Data were verified, coded, and analyzed using IBM-SPSS 20.0 (IBMSPSS Inc., Chicago, IL, USA). Data were presented as mean and standard deviation (SD) for quantitative variables, and frequency and percentage for qualitative variables. For quantitative groups' comparison analysis of variance (F-test) were used followed by Post-hoc test. While, for qualitative variables, chi-square $(\chi 2)$, Yates chi-square, or Fischer's exact (FE) tests, as appropriate, were used. Pvalue was considered significant at level $<0.05$.

\section{RESULTS}

The differences in averages of the heart rate, arterial blood pressure, amount of bleeding at operation, operation time, and visual analogue scale in the three studied groups [group I (bupivacaine 0.5\%), group II (ropavacine $0.75 \%$ ), and group III (xylocaine 2\%)] were statistically significant; $\mathrm{P}<001$ for each of them (Table 1). 
Table (1): Average of the heart rate, arterial blood pressure, amount of bleeding at operation, operation time, and visual analogue scale in the three studied groups

\begin{tabular}{|c|c|c|c|c|c|c|c|}
\hline Groups & $\begin{array}{c}\text { Group I } \\
\text { M } \pm \text { SD }\end{array}$ & $\begin{array}{c}\text { P- } \\
\text { Value }\end{array}$ & $\begin{array}{c}\text { Group II } \\
\mathbf{M} \pm \text { SD }\end{array}$ & $\begin{array}{c}\text { P- } \\
\text { Value }\end{array}$ & $\begin{array}{c}\text { Group III } \\
\mathbf{M} \pm \text { SD }\end{array}$ & $\begin{array}{c}\text { P- } \\
\text { Value }\end{array}$ & $\begin{array}{c}\text { Control } \\
\text { group }\end{array}$ \\
\hline $\begin{array}{c}\text { Average heart rate } \\
\text { (beat/min) }\end{array}$ & $71.4 \pm 0.36$ & 0.00 & $74.4 \pm 0.0$ & 0.00 & $74.8 \pm 0.2$ & 0.00 & $81.4 \pm 0.03$ \\
\hline $\begin{array}{c}\text { Average arterial } \\
\text { pressure (mmHg) }\end{array}$ & $71.0 \pm 0.0$ & 0.00 & $72.1 \pm 0.08$ & 0.00 & $75.5 \pm 0.0$ & 0.00 & $78.0 \pm 1.5$ \\
\hline $\begin{array}{c}\text { Average amount of } \\
\text { bleeding (ml) }\end{array}$ & $84.0 \pm 0.0$ & 0.00 & $78.0 \pm 0.0$ & 0.00 & $83.0 \pm 0.0$ & 0.00 & $116.0 \pm 0.00$ \\
\hline $\begin{array}{c}\text { Average operation } \\
\text { time (min) }\end{array}$ & $93.0 \pm 0.0$ & 0.00 & $95.0 \pm 0.0$ & 0.00 & $95.0 \pm 0.0$ & 0.00 & $99.0 \pm 0.00$ \\
\hline $\begin{array}{c}\text { Average visual } \\
\text { analogue scale (VAS) }\end{array}$ & $1.96 \pm 0.0$ & 0.00 & $2.28 \pm 0.0$ & 0.00 & $2.48 \pm 0.0$ & 0.00 & $3.6 \pm 0.00$ \\
\hline
\end{tabular}

The difference in the clarities of the operative field regarding bleeding amount (little-, mild-, and much-bleeding) in each of the three studied groups [group I (bupivacaine 0.5\%), group II (ropavacine $0.75 \%$ ), and group III (xylocaine 2\%)] was statistically insignificant $(\mathrm{P}=0.273$ Table 2).

Table (2): Clarity of the operative field regarding bleeding amount in the three studied groups

\begin{tabular}{|c|c|c|c|c|c|c|c|c|c|c|c|}
\hline \multirow{2}{*}{ Operative } & \multicolumn{2}{|c|}{ Group I } & \multirow[t]{2}{*}{$\begin{array}{c}p- \\
\text { value }\end{array}$} & \multicolumn{2}{|c|}{ Group II } & \multirow[t]{2}{*}{ p-value } & \multicolumn{2}{|c|}{ Group III } & \multirow[t]{2}{*}{$\begin{array}{c}\text { p- } \\
\text { value }\end{array}$} & \multicolumn{2}{|c|}{ Controls (IV) } \\
\hline & No. & $\%$ & & No. & $\%$ & & No. & $\%$ & & No. & $\%$ \\
\hline \begin{tabular}{|c|}
$\begin{array}{c}\text { Clear (little } \\
\text { bleeding) }\end{array}$ \\
\end{tabular} & 12 & 60.0 & 0.000001 & 8 & 40.0 & 0.0001 & 8 & 40.0 & 0.000001 & 0 & 0.0 \\
\hline $\begin{array}{l}\text { Moderate clarity } \\
\text { (mild bleeding) }\end{array}$ & 4 & 20.0 & & 4 & 20.0 & & 8 & 20.0 & & 0 & 0.0 \\
\hline $\begin{array}{c}\text { Little clarity } \\
\text { (much bleeding) }\end{array}$ & 4 & 20.0 & & 8 & 40.0 & & 4 & 40.0 & & 20 & 100.0 \\
\hline
\end{tabular}

The difference in the post-operative complications between the three studied groups [group I (bupivacaine 0.5\%), group II (ropavacine 0.75\%), and group III (xylocaine 2\%)] was statistically significant $(\mathrm{P}=0.01$-Table 3).

Table (3): Post-operative complications in the three studied groups

\begin{tabular}{|c|c|c|c|c|c|c|c|c|c|c|c|}
\hline \multirow{2}{*}{$\begin{array}{l}\text { Groups } \\
\text { Post- } \\
\text { operative } \\
\text { complications }\end{array}$} & \multicolumn{2}{|c|}{ Group I } & \multirow{2}{*}{$\begin{array}{c}\text { p- } \\
\text { value }\end{array}$} & \multicolumn{2}{|c|}{ Group II } & \multirow{2}{*}{$\begin{array}{c}\text { p- } \\
\text { value }\end{array}$} & \multicolumn{2}{|c|}{ Group III } & \multirow[t]{2}{*}{ p-value } & \multicolumn{2}{|c|}{ Controls (IV) } \\
\hline & No. & $\%$ & & No. & $\%$ & & No. & $\%$ & & No. & $\%$ \\
\hline Absent & 12 & 60.0 & 0.300 & 12 & 60.0 & 0.300 & 4 & 20.0 & 0.0005 & 16 & 80.0 \\
\hline Present & 8 & 40.0 & & 8 & 40.0 & & 16 & 80.0 & & 4 & 20.0 \\
\hline
\end{tabular}

The difference in types of the postoperative complications between the three studied groups [group I (bupivacaine
$0.5 \%$ ), group II (ropavacine $0.75 \%$ ), and group III (xylocaine 2\%)] was statistically significant $(\mathrm{P}=0.0003$-Table 4). 
Table (4): Types of post-operative complications in the three studied groups

\begin{tabular}{|c|c|c|c|c|c|c|c|c|c|c|c|}
\hline \multirow{2}{*}{$\begin{array}{l}\text { Types } \\
\text { Of complications }\end{array}$} & No. & $\%$ & & No. & $\boldsymbol{\%}$ & & No. & $\boldsymbol{\%}$ & & No. & $\%$ \\
\hline Headache & 0 & 0.0 & 0.0003 & 0 & 0.0 & 0.0003 & 12 & 60.0 & 0.106 & 8 & 40.0 \\
\hline Nausea & 4 & 20.0 & & 4 & 20.0 & & 4 & 20.0 & & 0 & 0.0 \\
\hline Vomiting & 0 & 0.0 & & 4 & 20.0 & & 0 & 0.0 & & 0 & 0.0 \\
\hline Dental numbness & 4 & 20.0 & & 0 & 0.0 & & 4 & 20.0 & & 0 & 0.0 \\
\hline
\end{tabular}

The difference in the analgesics early usage between the three studied groups [group I (bupivacaine $0.5 \%$ ), group II (ropavacine $0.75 \%$ ), and group III (xylocaine 2\%)] was statistically significant $(\mathrm{P}=0.00001$ - Table 5).

Table (5): Distribution of analgesics early usage in the three studied groups

\begin{tabular}{|c|c|c|c|c|c|c|c|c|c|}
\hline \multirow{2}{*}{$\begin{array}{l}\text { Analgesics } \\
\text { using }\end{array}$} & \multicolumn{2}{|c|}{ Group I } & \multicolumn{2}{|c|}{ Group II } & \multicolumn{2}{|c|}{ Group III } & \multicolumn{2}{|c|}{ Controls (IV) } & \multirow{2}{*}{$\begin{array}{c}\text { P- } \\
\text { Value }\end{array}$} \\
\hline & No. & $\%$ & No. & $\%$ & No. & $\%$ & No. & $\%$ & \\
\hline No & 12 & 60.0 & 4 & 20.0 & 2 & 10.0 & 0 & 0.0 & \multirow[b]{2}{*}{0.00001} \\
\hline Yes & 8 & 40.0 & 16 & 80.0 & 18 & 90.0 & 20 & 100.0 & \\
\hline
\end{tabular}

\section{DISCUSSION}

FESS is a safe technique and the ideal treatment for a variety of cases such as nasal polyps and rhinosinusitis (Fetta et al., 2017 and Rezaeian 2017). Further, it's crucial to maintain a clear, non-bloody field of surgery. Simultaneously, SPGB is currently used in patients who undergoing FESS under effect of GA to reduce bleeding and for post-operative pain relieving (Bhattacharyya et al., 2016). Also, SPGB is a known comfort, efficient, effective, and safe technique for managing craniofacial type of pain (Rezaeian et al., 2019).

In the current study, we showed that the averages of hemodynamic parameters (heart rate, arterial pressure, and bleeding amount) were less with statistically significant different from the controls. Also, there is risk of hemorrhage due to the increase in venous and arterial pressures.
Bhattacharyya et al. (2016) reported that during the surgery, average of HR $(74.1 \pm 3.9$ beats/min) in the SPGB group was statistically significant lower in the block group compared with the non-block group. Also, Gaafar et al. (2019) observed that the average of HR during all recorded times of surgery in the SPGB group were statistically significant lower in the block group compared with the control group. This could be explained, low HR permits more filling rate of the venous vessels, so, this lowering venous ooze in the field of surgery. Moreover, SPGB with local anesthetic agent could decrease the nasal sinuses' mucosal blood flow. This might be due to mucosal vasoconstriction and so a better clear field of the surgery (Gaafar et al., 2019). Meanwhile, Bhattacharyya et al. (2016) observed that during the surgery, average of blood loss in the SPGB group was statistically significant lower in the block 
group compared with the non-block group. Also, Gaafar et al. (2019) showed that the average of blood loss in the SPGB group was statistically significant lower in the block group compared with the nonblock group. Moreover, Kesimci et al. (2012) observed that amount of the blood loss was significantly less in the SPGB group. While, Rezaeian et al. (2019) clarified that blood loss was lower in the block group compared with the controls with in-statistically significant difference. Meanwhile, Bhattacharyya et al. (2016) showed that the intra-operative average of MAP in the SPGB group was statistically significant less in the block group compared with the non-block group. Also, Gaafar et al. (2019) found that the averages of MAP during all recorded times of surgery and post-surgery were statistically significant lower in the block group compared with the control group.

In the present study, we reported that means of the operation time in the three studied groups showed statistically significant differences from the controls. On the contrary, Rezaeian et al. (2019) found that surgery durations were higher in the block groups compared with the controls with non-statistically significant differences.

In the current study, we showed that means of VAS scores showed statistically significant differences. Also, the difference in- between the groups was statistically significant. Our results were accordant with Cho et al. (2011) and Bhattacharyya et al. (2016). Recently, Rezaeian et al. (2019) showed that the VAS scores were observed promptly after surgery; during recovery, 6, 12, and 24 hour. VAS scores were significantly smaller in the studied group compared with the controls. Also, they found that the difference in-between the groups were statistically significant.

Post-operative pain is a great important subject to deal with after all types of surgeries. Further, it's crucial to keep a satisfactory standard of analgesia after FESS (Gaafar et al., 2019). It is supposed that more than four-fifth $(86 \%)$ of patients who underwent surgical procedures experienced pain. Furthermore, $75 \%$ of the patients suffered from moderate to severe pain (Gan et al., 2014). Also, Shamil et al. (2018) cleared that for the first three hours after operation, there is significant decrease in the pain after endonasal surgery in patients who done SPGB compared with the controls. So, the SPGB extend the post-operative analgesia (Gaafar et al., 2019).

A small number of researches, to the best of our knowledge, have been done to evaluate the effectiveness the SPGB. Almost of these researches have pointed that using of the SPGB could give significant results in reducing pain in patients who underwent FESS (Rezaeian et al., 2019). The researchers suspect that post-operative pain in patients underwent SPGB with GA group could be decreased compared to the controls without SPGB (Al-Qudah, 2016). Cho et al. (2011) pointed that using of bupivacaine in the SPGB plus general anesthesia during the FESS, post-operative pain could be reduced, but with in-statistically significant difference.

In the current study, we reported that the differences between percentages of post- operative complications were statistically insignificant among the 
studied groups I and II, and the controls; while the differences between percentages in group III and the controls was statistically significant higher in the group III. At the time, we confirmed that headache $(60.0 \%)$ was the commonest complication in group III, nausea $(20.0 \%)$ and dental numbness $(20.0 \%)$ in group I, and nausea $(20.0 \%)$ and vomiting $(20.0 \%)$ in group II. Gaafar et al. (2019) found that nausea, as post-operative complication, was significantly lower in SPGB group (13.04\%) compared with the controls. Also, Kesimci et al. (2012) and Rezaeian et al. (2019) cleared that in the SPGB group the complications (nausea, vomiting, headache, and visual disturbance) were less than the controls, but with insignificant differences. Moreover, Bhattacharyya et al. (2016) observed that the post-operative complications in the SPGB group were dental numbness (13.3\%) and retro-ocular pressure $(6.7 \%$ ) in SPGB group.

In the present study, we found that the studied patients in groups I (bupivaciane $0.5 \%$ ), II (ropavacine 0.75\%), and III (xylocaine 2\%) used post-operative rescue analgesics less than the controls. However, the only significant difference was the bupivaciane $0.5 \%$ group. Rezaeian et al. (2019) cleared that only $20.0 \%$ of their studied cases used saving analgesics compared with $60.0 \%$ of the controls with statistically significant difference. Also, Bhattacharyya et al. (2016) found that the first needed postoperative analgesic dose was required for pain relief after $12.3 \pm 3.6$ hour in the SPGB group with statistically significant low figure than that in the non-block group. Gaafar et al. (2019) found that time for first request of analgesia was significantly longer in block group compared with the controls. Similarly, DeMaria et al. (2012) cleared that SPGB plus general anesthesia was suitable in reducing the need for opiates after the FESS.

\section{CONCLUSION AND RECOMMENDATIONS}

Bilateral SPGB in FESS under GA was proved to be a simple, easy, helpful and of great importance in reducing the heart rate, arterial blood pressure, intraoperative bleeding, operation time, VAS, and suitable operative field in the studied groups. Moreover, its drawbacks were minimum. Further, bupivacaine $0.5 \%$ was significantly reducing analgesics usage. Also, xylocaine $2 \%$ was significantly reducing post-operative complications. More studies are needed to be done on large number of patients and on other types of nasal surgeries.

\section{Conflict of Interest:}

Authors declare that there was no conflict of interest.

\section{REFERENCES}

1. Al-Qudah M. (2016): Endoscopic sphenopalatine ganglion blockade efficacy in pain control after endoscopic sinus surgery. Int Forum Allergy Rhinol., 6(3):334-338.

2. Bhattacharyya $S$, Tewari MK, Ghosh S, Chakroborty J. and Das W, Barman U. (2016): Evaluation of the efficacy of bilateral sphenopalatine ganglion block in endoscopic sinus surgery under general anesthesia: a randomized prospective controlled trial. Res Opin Anesth Intens Care., 3:173-178.

3. Cho DY, Drover DR, Nekhendzy V, Butwick AJ, Collins J. and Hwang PH. (2011): The effectiveness of preemptive sphenopalatine ganglion block on postoperative pain and functional outcomes after functional 
endoscopic sinus surgery. Int Forum Allergy Rhinol., 1(3):212-218.

4. DeMaria S, Govindaraj S, Chinosorvatana N, Kang S. and Levine AI. (2012): Bilateral sphenopalatine ganglion blockade improves postoperative analgesia after endoscopic sinus surgery. Am J Rhinol Allergy., 26(1):e23-e27.

5. Di Mauro R, Lucci F, Martino F, Silvi MB, Gidaro E. and Di Lorenzo S. (2018): The role of intraoperative stroke volume variation on bleeding during functional endoscopic sinus surgery. Minerva Anestesiol., 84[11]:12461253.

6. Ekici NY. and Alagöz S. (2019): The effectiveness of endoscopic sphenopalatine ganglion block in management of postoperative pain after septal surgery. Int Forum Allergy Rhinol., 1521-1525.

7. Fetta M, Tsilis NS, Segas JV, Nikolopoulos TP. and Vlastarakos PV. (2017): Functional endoscopic sinus surgery improves the quality of life in children suffering from chronic rhinosinusitis with nasal polyps. Int $\mathrm{J}$ Pediatr Otorhinolaryngol., 100:145-148.

8. Gaafar TY, El Sawy AH, Zanfaly HE. and Abdelaziz MA. (2019): Bilateral Sphenopalatine Ganglion Block versus Intravenous Clonidine Premedication for Surgical Field Improvement and Postoperative Pain Relief in Endoscopic Sino-Nasal Surgery. ZUMJ, 25(6): 847-857.

9. Gan TJ, Habib AS, Miller TE, White W. and Apfelbaum JL. (2014): Incidence, patient satisfaction, and perceptions of postsurgical pain: results from a US national survey. Curr Med Res Opin., 30(1):149-160.

10. Huang Z, Hwang P, Sun Y. and Zhou B. (2015): Steroid-eluting sinus stents for improving symptoms in chronic rhinosinusitis patients undergoing functional endoscopic sinus surgery. Cochrane Database Syst Rev., [6]: CD010436.

11. Kesimci E, Ozturk L, Bercin S, Kiris M, Eldem A. and Kanbak O. (2012): Role of sphenopalatine ganglion block for postoperative analgesia after functional endoscopic sinus surgery. Eur Arch Otorhinolaryngol., 269(1):165-169.

12. Mayhew D, Mendonca V. and Murthy BVS. (2019): A review of ASA physical status historical perspectives and modern developments. Anaesthesia., 74:373-379.

13. Rezaeian A. (2017): Administering of pregabalin and acetaminophen on management of postoperative pain in patients with nasal polyposis undergoing functional endoscopic sinus surgery. Acta Otolaryngol., 137(12):1249-1252.

14. Rezaeian A, Hashemi SM. and Dokhanchi ZS. (2019): Effect of sphenopalatine ganglion block with Bupivacaine on postoperative pain in patients undergoing endoscopic sinus surgery. Allergy Rhinology., 10:1-5.

15. Robbins MS, Robertson CE. and Kaplan E. (2016): The sphinoplatine ganglion: Anatomy, pathophysiology, and therapeutic targeting in headache. Headache., 65: 240-258.

16. Shamil E, Rouhani MJ, Basetti S, Bast F, Hopkins C. and Surda P. (2018): Role of local anesthetic nerve block in endoscopic sinus surgery: A systematic review and metaanalysis. Clin Otolaryngol., 43(5):1201-1208.

17. Wormald PJ, Athanasiadis T, Rees G. and Robinson S. (2005): An evaluation of effect of pterygopalatine fossa injection with local anesthetic and adrenaline in the control of nasal bleeding during endoscopic sinus surgery. Am J Rhinol., 19(3):288-292.

18. Xiong BJ, Xu Y, Jin GL, Liu M, Yang J. and Yu CX. (2017): Analgesic effects and pharmacologic mechanisms of the Gelsemium alkaloid koumine on a rat model of postoperative pain. Sci Rep., 7(1):142-149. 


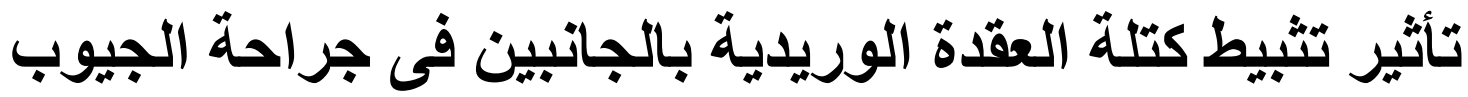

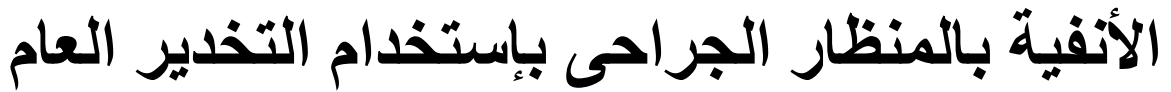

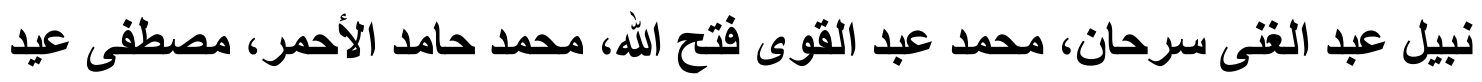
محمد، مدحت مصطفى خليفه*

قسم الآنف والأذن والحنجرة و قسم التخدير والرعاية المركزة*، كلية الطب، جامعة الآزهر

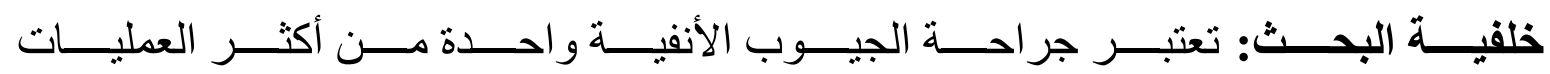

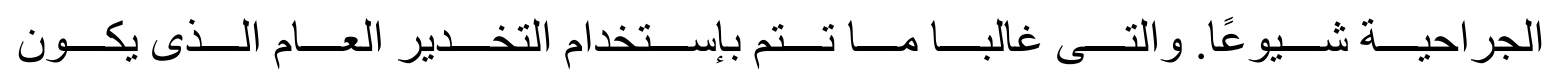

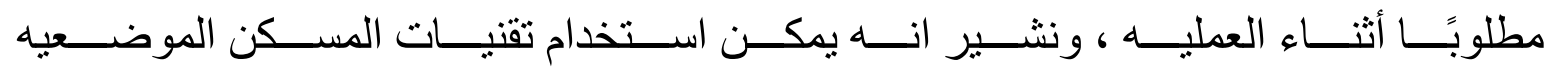
أثناء استخدام المخدر العام مما يمنع المنبهات الضارة اثناء وبعد الجر احة.

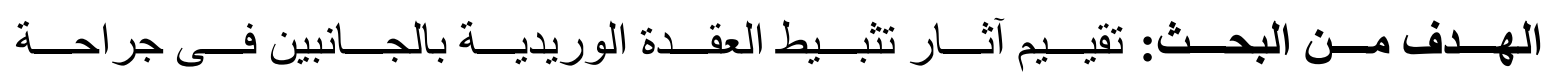

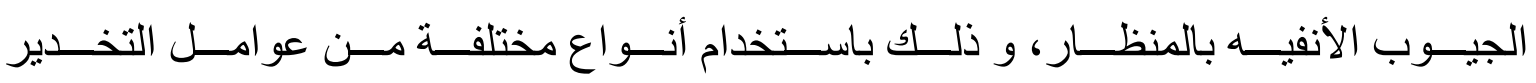
الموضعي.

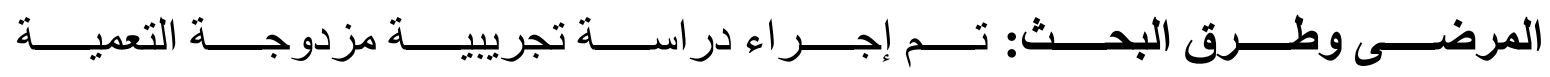

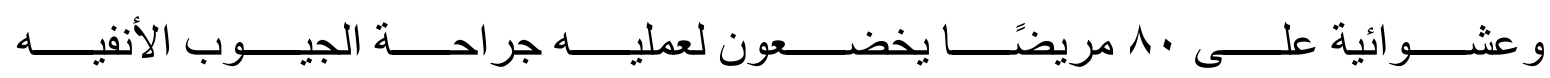
بالمنظار مع تثبيط العقدة الوريدية بالجانبين تحت المخدر العام.

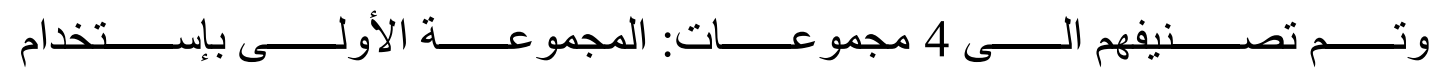

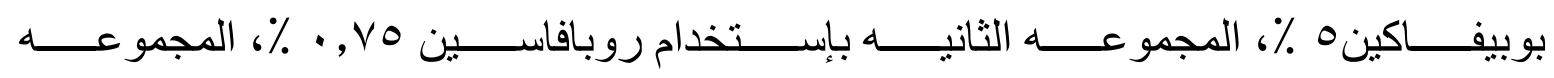

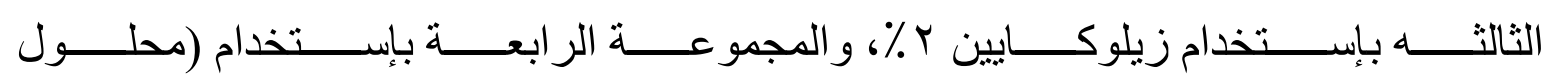

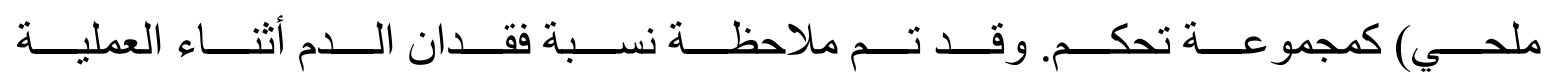

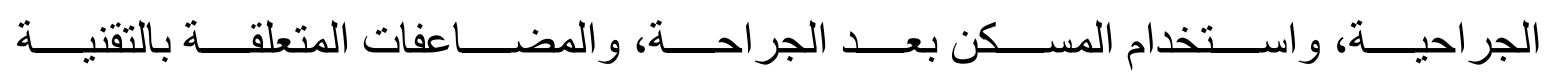
المستخدمة.

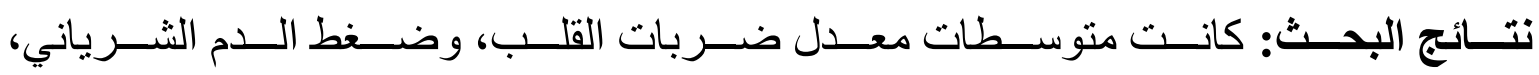

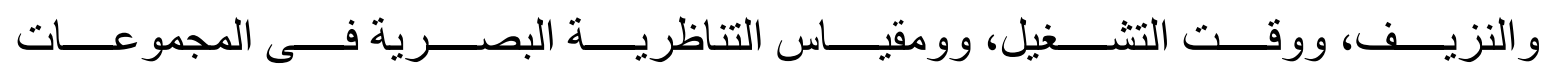

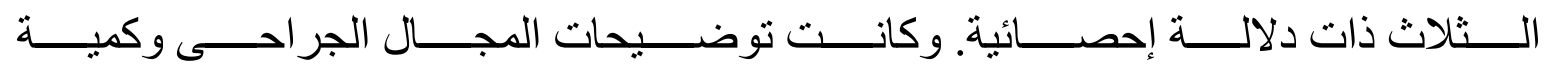




\section{EFFECTS OF BILATERAL SPHENOPALATINE GANGLION BLOCK...}

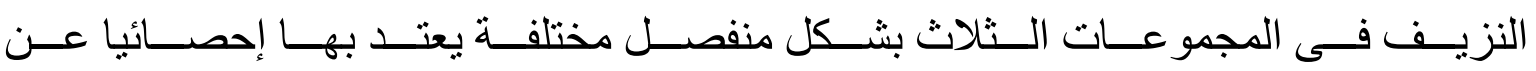

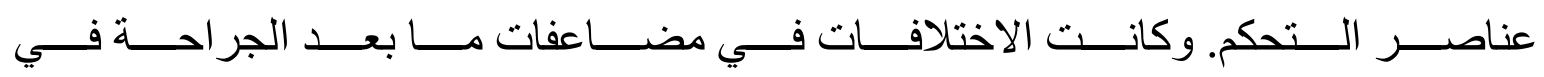

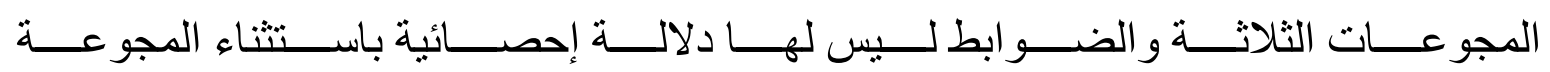

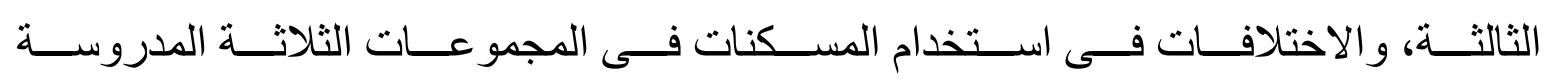
و الضو ابط ليس لها أهمية إحصائية بإستثناء المجمو عة الأولى.

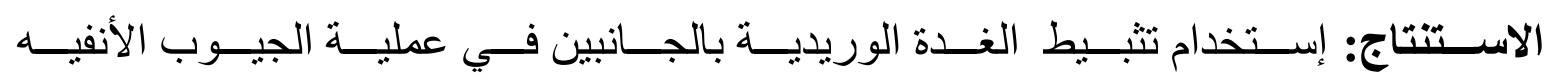

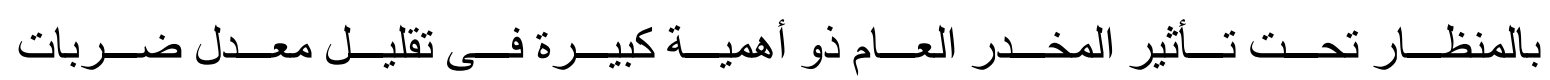

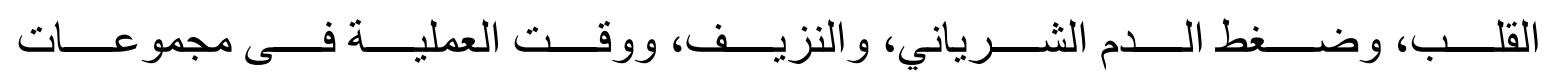

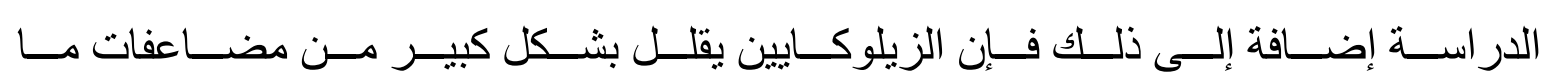
بعد الجر احة، كما أن بوبيفاكين يقلل بشكل كبير من إستخدام المسكن. 